\title{
ERRATUM
}

\section{Erratum to: Estimation of carbon storage based on individual tree detection in Pinus densiflora stands using a fusion of aerial pho- tography and LiDAR data}

\author{
KIM So-Ra ${ }^{1}$, KWAK Doo-Ahn ${ }^{1}$, LEE Woo-Kyun ${ }^{1 *}$, SON Yowhan ${ }^{1}$, BAE Sang-Won ${ }^{2}$, \\ KIM Choonsig $^{3}, \&$ YOO Seongjin ${ }^{1}$ \\ ${ }^{1}$ Division of Environmental Science and Ecological Engineering, Korea University, Seoul 136-701, Korea; \\ ${ }^{2}$ Forest Practice Research Center, Korea Forest Research Institute, Kyeonggi-Do 487-821, Korea, \\ ${ }^{3}$ Departement of Forest Resources, Jinju National University, Jinju 660-758, Korea
}

Erratum to: SCIENCE CHINA Life Sciences, July 2010 Vol.53 No.7: 885-897

doi: $10.1007 / \mathrm{s} 11427-010-4017-1$

In the online version of the article the name of the third author is incorrect. The correct name is LEE Woo-Kyun.

The online version of the original article can be found at

http://dx.doi.org/10.1007/s11427-010-4017-1 